\title{
Management of pediatric corneal limbal dermoids
}

This article was published in the following Dove Press journal:

Clinical Ophthalmology

27 March 2013

Number of times this article has been viewed

\begin{abstract}
Amir Pirouzian ${ }^{1,2}$
'Tayani Institute, Division of Ophthalmology and Cornea, Mission Viejo in affiliation with Children's Hospital of Orange County at Mission Hospital, CA, USA; ${ }^{2}$ Rady's Children's Hospital of San Diego, San Diego, CA, USA
\end{abstract}

Abstract: This paper reviews the data in the published literature (PubMed from 1937 to 2011) concerning the medical and surgical management of pediatric limbal dermoids. Current standard medical treatment for grade I pediatric limbal dermoids (ie, with superficial corneal involvment) is initially conservative. In stages II (ie, affecting the full thickness of the cornea with/without endothelial involvement) and III (ie, involvement of entire cornea and anterior chamber), a combination of excision, lamellar keratoplasty, and amniotic membrane and limbal stem cell tranplantation are advocated. Combinations of these approaches seem to yield better and more stable long-term ocular surface cosmesis and fewer complications in comparison with traditional methods of excision and lamellar keratoplasty. Management of amblyopia (i.e. occlusion treatment, chemical penalization with/without spectacle wear, etc) must continue after surgical excision to yield optimal results when or if the surgery is done at a younger age.

Keywords: limbal dermoid, amniotic membrane, surgical management, tissue adhesive

\section{Introduction}

Epibulbar dermoids are the most common episcleral choristomas, ie, congenital overgrowth of normal tissues by collagenous connective tissue covered by epidermoid epithelium in an abnormal location, and involving the globe in children. These lesions may present unilaterally or bilaterally, and the majority $(>85 \%)$ are located in regions of the bulbar conjunctiva, limbus, cornea, and/or caruncles. ${ }^{1}$

\section{Histopathology, incidence, and pathogenesis}

Epibulbar dermoids may present as a single lesion or as multiple lesions. They are marginally vascularized, smooth, whitish lesions with sebaceous components generally located in the inferotemporal globe or temporal limbus..$^{2-5}$ Epibulbar choristomas are thought to arise from an early embryological anomaly (occurring at 5-10 weeks' gestation) resulting in metaplastic transformation of the mesoblast between the rim of the optic nerve and surface ectoderm. ${ }^{6}$

Anatomically, epibulbar dermoids have been classified into three grades. ${ }^{7}$ This form of grading allows clinicians to take a more stepwise approach to the clinical and surgical management of such lesions. Grade I limbal dermoids are superficial lesions measuring less than $5 \mathrm{~mm}$ and are localized to the limbus (Figure 1). Such lesions may lead to development of anisometropic amblyopia, with slow growth resulting in oblique astigmatism and flattening of the cornea adjacent to the lesion. Grade II limbal dermoids are larger lesions covering most of the cornea and extending deep into the stroma down to Descemet's membrane without involving it (Figure 2). Grade
Correspondence: Amir Pirouzian

Tayani Institute, Division of

Ophthalmology, 26726 Crown Valley

Parkway, Mission Viejo, CA 9269I, USA

Tel +l 8582480747

Fax + I 94949603604

Email apirouzian@gmail.com 


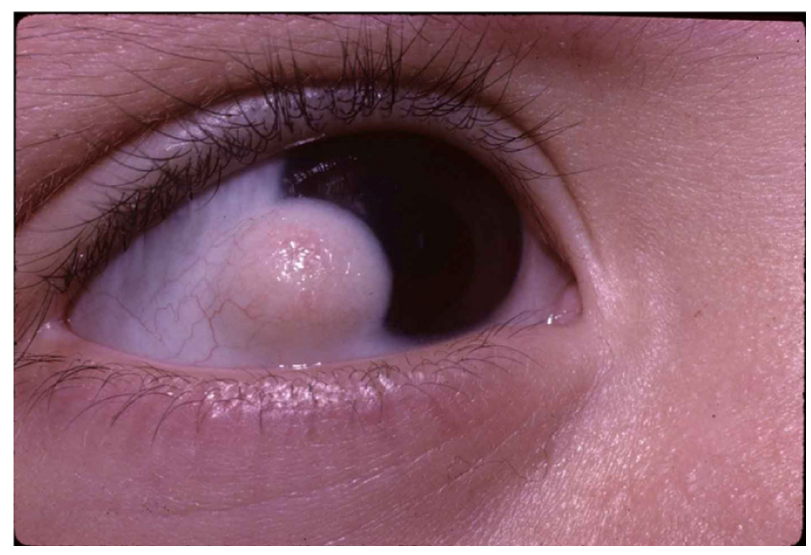

Figure I Grade I limbal dermoid.

III limbal dermoids, the least common of all the presenting dermoids, are large lesions covering the whole cornea and extending through the histological structures between the anterior surface of the eyeball and the pigmented epithelium of the iris (Figure 3).

A study by Nevares et al indicates that the majority ( $76 \%)$ of ocular dermoids occur at the inferotemporal bulbar location of the eye, with the other $22 \%$ reported to occur superotemporally. ${ }^{4}$ In a study by the Armed Forces Institute of Pathology, 75 of 1016 such lesions were documented to be epibulbar choristomas, with more than $80 \%$ of lesions noted to be located temporally and inferiorly. ${ }^{8}$ In another study at the Wilmer Eye Institute of Pathology, choristomas comprised $33 \%$ of all epibulbar lesions in individuals younger than 16 years of age. ${ }^{9}$ This study showed that these lesions may sometimes be associated with other ocular findings, including scleral/corneal staphyloma, aniridia, congenital aphakia, cataract, and microphthalmia. ${ }^{9}$ It has been reported that choristomas may or may not be associated with systemic conditions and other syndromes,

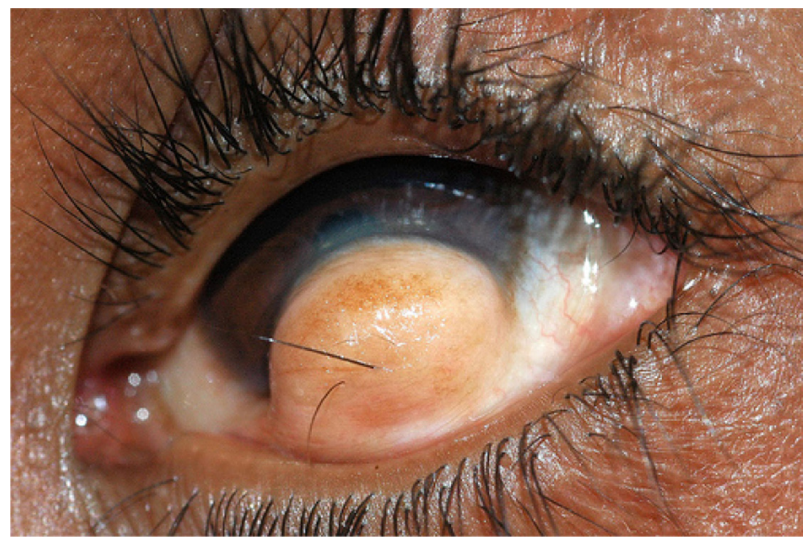

Figure 2 Grade II limbal dermoids involving nearly the entire depth of cornea up to Descemet's membrane.

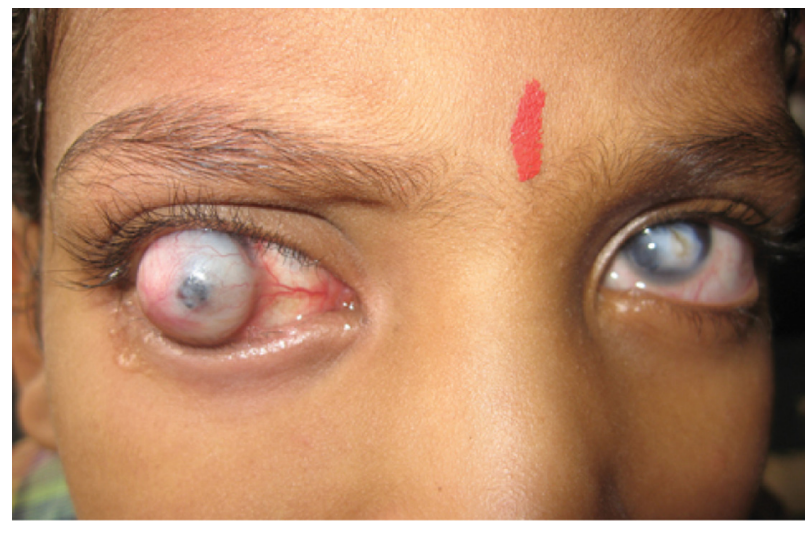

Figure 3 Grade III dermoid with staphyloma.

such as ring dermoid syndrome with conjunctival extension, preauricular tags, palpebral coloboma, Goldenhar's syndrome (preauricular fistulae, preauricular appendages, and epibulbar dermoids or lipodermoids), and the mandibulofacial dysostosis of Franceschetti syndrome. ${ }^{9,10}$ Goldenhar's syndrome has been expanded further to include vertebral anomalies and is now named Goldenhar-Gorlin syndrome. ${ }^{9}$ Because epibulbar choristomas may occasionally be associated with epidermal nevus syndrome, one must pay close attention to the presenting signs of this syndrome. Of note, a subgroup of these lesions, ie, sebaceous nevus, is known to undergo malignant transformation. ${ }^{11}$ Histologically, limbal dermoids show hair follicles and sebaceous gland acini within a discrete elevated nodule of fibrous connective tissue $^{12}$ (see Figure 4).

\section{Genetics and inheritance}

The pattern of inheritance is quite variable in epibulbar choristomas. They can be autosomal dominant, recessive, $\mathrm{X}$-linked, or multifactorial. ${ }^{2}$

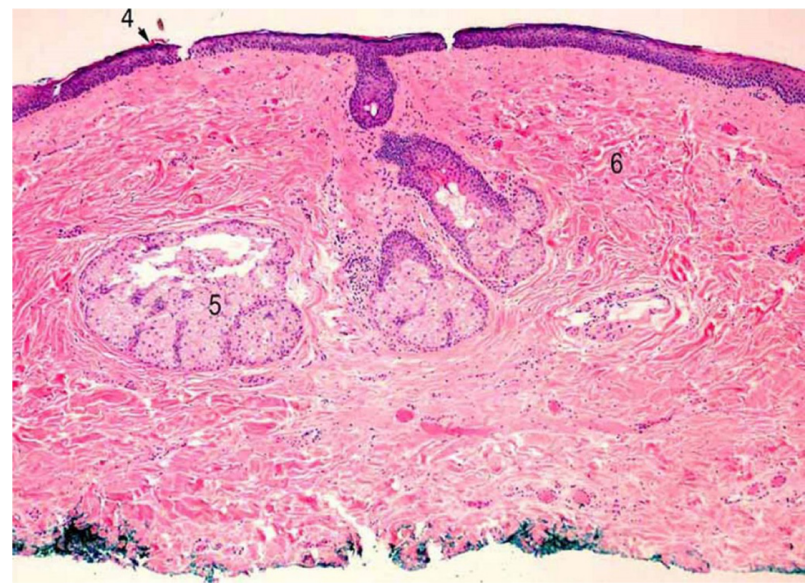

Figure 4 Histological cross-section of ocular dermoid. 


\section{Medical management}

Medical management is generally reserved for grade I dermoids which are smaller lesions in terms of diameter and height, inducing only mild astigmatism of $<1 \mathrm{D}$ with minimal surface irregularity, and parents report relatively good compliance with spectacle correction. The main recommendation noted in the literature is to "leave these lesions alone", ${ }^{13,14}$ and one would tend to agree. Essentially small asymptomatic grade I limbal dermoids should not be removed because they may lead to postoperative scarring and development of pseudopterygium. It is recommended that these children undergo close clinical observation with serial examinations in the office, not only to monitor stability but also to provide reassurance for parents.

During each office examination, which should be performed once every $2-3$ months, visual acuity and presence or absence of amblyopia must be established and advice should be given on occlusion therapy. The size of the lesion, ideally captured and measured by digital photography, visual acuity, stereo acuity, cycloplegic refraction, and gonioscopy, need to be addressed, whenever possible. These serial examinations should continue in all cases unless patients meet the following criteria for surgical intervention: development of clinically significant anisometropia; presence of amblyopia is impending or established; lack of compliance with either follow-up or spectacle correction is recognized; growth of limbal dermoid induces marginal dellen, resulting in surface disease and increasing anisometropic astigmatism; and esthetic considerations. When any of the above conditions or combination of conditions is noted, surgery should be considered and thoroughly discussed with the parents, including the potential risk of scarring, the requirement for ongoing treatment of amblyopia after surgery, need for spectacle or contact lens wear, possible repeat surgery, and loss of vision.

\section{Patient selection and preoperative evaluation}

Despite their benign nature, grade I epibulbar/limbal dermoids may affect vision by gradually inducing corneal astigmatism, leading to profound anisometropic amblyopia, which is mostly reversible in the early years. Conservative management by observation may not be a suitable option for such lesions. ${ }^{13}$ Enlarging perilimbal dermoids may also cause disturbance of the ocular surface tear film, forming dellens which result in surface irritation, discomfort, and rubbing of the eye. ${ }^{13}$ There is debate among pediatric and corneal surgeons about the appropriate timing of excision and the optimal method for surgical repair of the corneal defect following resection. ${ }^{15-17}$ The optimal timing of surgical excision appears to depend on multiple factors, including the original size of the lesion, its rate of growth, and the anatomical area involved, as well as request for removal for psychosocial reasons. ${ }^{15-17}$ Overriding clinical indications for surgery include tumor size and growth, secondary corneal defect, unresponsive amblyopia, and psychosocial and cosmetic considerations. A thorough history should be taken from the parents, and serial in-office examinations with cycloplegic retinoscopy must be performed to monitor the size of the corneal dermoid. Presence or lack of amblyopia must be established. If in-office examinations or serial evaluations are not feasible, clinical examination should be done under general anesthesia along with an anterior segment high resolution B-scan (ultrasound biomicroscopy) to assess for involvement of Descemet's membrane. These steps are necessary in order to plan for the appropriate surgical approach. ${ }^{18-20}$ Hoops et al advocate meticulous biomicroscopic ultrasound examination to improve the depth of corneal penetration for sound waves. Their study shows that dermoids produce strong sound attenuation, reducing the visibility of deep corneal structures and in particular Descemet's membrane. ${ }^{19}$

\section{Indications for surgery}

There are recognized clinical indications for proceeding with surgical excision and anterior surface reconstruction in patients with a grade I limbal dermoid. For example, if a child or the parents are not compliant with wearing of corrective spectacles, even for mild astigmatism, one may consider surgical excision in the presence of amblyopia. However, if adherence with spectacle wear is good in the setting of large, regular, and oblique astigmatism, and adequate follow-up for clinical treatment of amblyopia is possible, surgeons may opt to defer surgical intervention. In the presence of amblyopia, one must exhaust all efforts to treat amblyopia medically, including with spectacles and occlusion therapy. Conversely, if the astigmatism is irregular or if the patient is not compliant with wearing of spectacles, surgical excision and reconstructive steps are indicated. Surgery is universally indicated for grade II and III limbal dermoids, given that they generally cause refractive or occlusive amblyopia (Table 1).

\section{Surgical management}

A variety of surgical techniques has been described in the literature, ranging from simple excision to lamellar 
Table I Indications for primary surgical intervention in grade I limbal dermoids

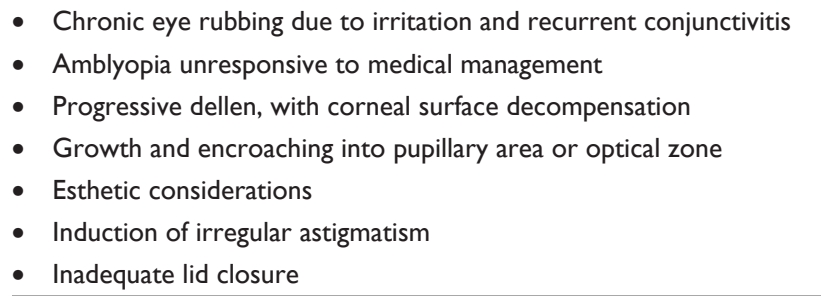

and/or penetrating keratoplasty with relaxing corneal incision, depending on the grade of the lesion. Depth, size, and site of such lesions are critical factors. Other techniques include corneal-limbal scleral donor graft transplantation and surgical resection followed by reconstructive sutureless multilayered amniotic membrane transplantation. ${ }^{15-17,21-27}$

In a retrospective review of 50 patients with ocular dermoids identified in the literature from 1970 to 1985, Nevares et al reported that, in children aged 2-19 months, $68 \%$ comprised epibulbar dermoids, and advocate excision of these lesions with simple superficial keratectomy. ${ }^{4}$ These authors also cautioned that the graft may opacify over time and a second surgical graft may be necessary. No other complications were noted, but visual acuity and long-term results were not reported. Burillon et $\mathrm{al}^{5}$ reviewed the records of 12 patients with solid ocular tumors between 1985 and 1993, reporting that six lesions could be easily shaved off the cornea and adjacent sclera to improve the appearance of the eye. Visual acuity remained unchanged. In another three cases, they reported that a degree of refractive amblyopia persisted after late surgery, and visual acuity continued to be less than 20/200. In another two cases, early corneolamellar keratoplasty for large limbal dermoids improved bestcorrected visual acuity (BCVA). They also suggested that early surgery with simple local resection (combined with a conjunctival flap in order to cover the exposed area) may be preferred to lamellar keratoplasty.

In a retrospective review of 17 patients with limbal dermoids, Robb et a ${ }^{13}$ found that $13(76 \%)$ had astigmatism of 1.0 D or greater in the involved eye. In all but one patient, the minus cylinder axis of the astigmatism coincided with the location of the dermoid. Thirteen patients underwent simple surgical excision to remove their dermoid at ages ranging from 8 months to 15 years. The astigmatism persisted postoperatively, with little change in orientation or amount, regardless of patient age at the time of surgery. No complications were reported in this study.
In 1961, Bourne treated a series of four pediatric patients with grade II limbal dermoid by direct excision followed by lamellar keratoplasty using a 5-7 $\mathrm{mm}$ trephine with a good outcome. ${ }^{14} \mathrm{He}$ reported no herniation of tissues posterior to the repaired site and no graft failures, but did not provide any details on visual acuity. Although the results of surface reconstruction was satisfactory, it is possible that the final visual acuity was limited because of the older age of the patients and lack of follow-up treatment for amblyopia in some cases.

Zaidman et al reported on two-stage excision of a protuberant congenital corneal dermoid that extended into the anterior chamber in an infant aged one month. ${ }^{15}$ A $12 \mathrm{~mm}$ lamellar keratectomy was followed 3 months later by a smaller $(8 \mathrm{~mm})$ penetrating keratoplasty. These authors considered that this technique minimized the complications associated with large corneal transplants and increased the chance of long-term success. The graft remained transparent without complication or rejection, and the infant continued to maintain constant fixation initially. Panton and Sugar reviewed the clinical files of 10 patients who had undergone simple excision of a unilateral grade I epibulbar limbal dermoid. Preoperatively, all of the affected eyes had significantly worse visual acuity $(P<0.02)$ and more astigmatism $(P<0.01)$ than the contralateral eyes. Postoperatively, every patient showed cosmetic improvement. Of the eight patients for whom both preoperative and postoperative visual acuity measurements had been obtained, six showed minimal change ( $\leq$ one line) and two showed improvement ( $\leq$ two lines). Surgical complications included persistent epithelial defects $(40 \%)$ and peripheral corneal vascularization and opacity $(70 \%) .{ }^{16}$ Kaufman et al have also discussed in detail their selective surgical approach to the treatment of various corneal limbal dermoids in children. ${ }^{17}$

Scott et al reported that seven of their 11 patients had a single inferotemporal limbal dermoid, with one patient having two dermoids in one eye. Their median follow-up time was 21.6 months, and eight of the 11 patients showed good or excellent cosmetic results with minimal interface haze and no vascularization. Vascularization developed postoperatively in two cases with previously excised lesions. One of these cases developed graft infection, underwent subsequent debridement, and had an opaque graft. BCVA was maintained or slightly improved in nine of these patients. For the group overall and most individual patients, mean astigmatism, spherical equivalent, and refraction, as assessed by surgically-induced refractive change and $\mathrm{h}$-vector analysis, were not significantly changed. ${ }^{21}$ 
Shen et al, in their retrospective Taiwanese study of 10 patients aged 5.7-22.4 years with grade II limbal dermoids who underwent lamellar keratoscleroplasty with full-thickness central corneal grafts, reported that the mean earliest BCVA and latest postoperative BCVA were 6/30 and 6/10, respectively, and the improvement in BCVA after surgery and treatment for amblyopia was $4.9 \pm 3.6$ lines on the Snellen chart. Patients with preoperative astigmatism $\geq 6.0 \mathrm{D}$ $(9.7 \pm 1.0 \mathrm{D} ; \mathrm{n}=4)$ were found to have a marked decrease in astigmatism of $5.2 \pm 1.7 \mathrm{D}$ after surgery. Patients with preoperative astigmatism $<6.0 \mathrm{D}(3.4 \pm 0.2 \mathrm{D} ; \mathrm{n}=5)$ were found not to have a significant increase in astigmatism after surgery. Significant corneal opacity was found in one patient after surgery, and a mild bluish scleral hue was noted in three patients. Surgical complications included prolonged re-epithelialization, interface neovascularization, graft rejection, and steroid-induced glaucoma. ${ }^{22}$

Watts et $\mathrm{al}^{23}$ performed a study in Toronto in patients of mean age $4.4 \pm 3.8$ years at the time of surgery. Dermoid excision and lamellar keratoplasty was performed in 48 eyes, simple excision was performed in two eyes, and a penetrating graft was performed in one eye. The mean graft size $(6.6 \pm 1.2 \mathrm{~mm}$, range $3.5-10 \mathrm{~mm})$ was inversely related to the age of the patient $(P=0.04)$. Microperforations were noted in three eyes on excision of the dermoid. Opacification of part of the graft was seen in $10.2 \%$ of eyes (five of 49) with a mild haze in three eyes. Postoperatively, $96.7 \%$ of eyes (29 of 30) had visual acuity $\geq 6 / 24,86.7 \%$ (26 of 30 ) had visual acuity $\geq 6 / 12$, and one eye had visual acuity of $6 / 120$. The size of the graft correlated inversely with visual acuity $(P=0.03)$. Preoperative and postoperative refraction was recorded in 23 patients, showing that astigmatism $>1 \mathrm{D}$ was present in $43.4 \%$ preoperatively and in $60 \%$ postoperatively $(P=0.6)$. There was no association between age at the time of surgery $(P=0.6)$ or graft size $(P=0.2)$ and the presence of postoperative astigmatism.

Simple excision of grade I and II corneal dermoids has typically been shown to result in a persistent epithelial defect, corneal vascularization, and scar formation, which is now thought to occur as a result of a cascade of events related to focal marginal limbal stem cell deficiency at the site of dermoid excision. In a more recent study, Hong et al used autologous limbal stem cell transplantation in two patients with good results, with none of the aforementioned complications or visual loss. ${ }^{28}$ Tseng et al reported in their study of thirty-one eyes of 26 consecutive patients whom had cytologically proven limbal stem cell deficiency resulting from chemical burns that amniotic membrane transplantation
(AMT) alone is sufficient and hence superior to allograft limbal transplantation (ALT) for partial limbal deficiency with superficial involvement. ${ }^{29}$ They report, however, that in total limbal stem cell deficiency, additional ALT would be needed. They proceed to report that except for the 2 eyes with atopy, all amniotic membrane-covered surfaces showed rapid epithelialization (in 2 to 4 weeks) and reduced inflammation, vascularization, and scarring, and the surfaces became smooth once again. ${ }^{29}$ Further, Lazzaro and Coe reported a good cosmetic result after excision of a grade II limbal dermoid combined with placement of a $400 \mu \mathrm{m}$ pericardial patch graft. No complication was noted, but no details on visual acuity was reported. ${ }^{30}$

A significant concern about simple excision of such tumors is the fact that there may be a tail extending beyond the visible lesion to a larger mass in the orbit, as a result of which incomplete excision and/or perforation of the globe may ensue. ${ }^{14}$ Therefore, all lesions suspicious for posterior tail extension must be evaluated carefully prior to surgery using appropriate imaging. Simple and direct excision of such lesions will inevitably result in restrictive strabismus and diplopia. ${ }^{18-20}$ Panda et $\mathrm{al}^{24}$ reported results of lamellar keratoplasty (sectrol, annular, or central lamellar keratoplasty) in 155 consecutive eyes with limbal epibulbar dermoids having undergone lamellar keratoplasty from 1977 to 1998 according to the size and location, the dermoids were managed surgically either by sectoral, annular, or central lamellar keratoplasty. They reported all but 16 eyes improved cosmetically. All the patients showed reduction in astigmatism and 116 eyes improved functionally. They conclude in order to avoid development of amblyopia, surgery at an early age is preferred. Mader and Stulting have reported use of deep excision and deep lamellar keratoplasty with placement of eight equally spaced 10-0 interrupted or running nylon sutures for surgical removal of a grade II limbal dermoid in a single case report. ${ }^{25}$ Visual acuity remained unchanged and no complications were noted.

A number of more recent reports have shown that tissue grafting using fresh amniotic membrane with or without a limbal allograft is appropriate for ocular and corneal surface reconstruction in grade I limbal dermoids.

Building on the meticulous work done by Koizumi et al and Kim and Park, Pirouzian et al recently reported that surgical management of grade I pediatric perilimbal dermoids using lamellar dissection and consecutive reconstruction of the defective area with fibrin glue-assisted multilayered amniotic membrane (AmnioGraft ${ }^{\text {TM }}$, Bio-tissue Inc, Miami, FL, USA) results in a successful clinical and esthetic 
outcome, with no complications. ${ }^{26}$ This surgical technique has been described in detail elsewhere. ${ }^{26,27}$ Refractive error remained unchanged after surgery, and occlusion therapy was initiated postoperatively along with spectacle correction for amblyopia. The top amniotic membrane can be secured safely into the surrounding healthy corneal tissue using 10-0 vicryl sutures in order to avoid any possibility of graft dislocation. The rationale for using multilayered amniotic membrane transplantation is to achieve complete volumetric filling of the defective area, which should be equal in height to that of the surrounding healthy corneal tissue. Extensive corneal defects appear to show improved healing following multilayered amniotic membrane transplantation and augmentation. ${ }^{27}$ Koizumi et al conclude in their study cellular outgrowth from the central explants ( $\mathrm{n}=10)$ after 14 days in culture showed denuded amniotic membrane appeared to be an excellent substrate for the cultivation of corneal epithelial cells, with a view to transplantation. Limbal cells cultivated on denuded amniotic membrane formed a nicely stratified layer that adhered well to the underlying amniotic membrane. ${ }^{31}$ Further, multiple studies have shown that fresh amniotic membrane has an anti-inflammatory action because it contains interleukin-1 receptor antagonists as well as an antiscarring action because it contains various neurotransmitters, neuropeptides, and neurotrophins. Similar studies have shown that the amniotic stromal matrix membrane maintains the keratocyte phenotype during ex vivo expansion, and the amniotic membrane has been used in several protocols as a substrate to expand limbal epithelial progenitor cells directly from the limbal epithelium..$^{36}$ The success of both these approaches strongly supports the concept that the amniotic membrane functions as an alternative progenitor cell niche. ${ }^{36}$ Indications for fresh amniotic membrane transplantation with or without limbal allografting in the treatment of diseases of the ocular surface and corneal surface reconstruction have been described in cicatricial ocular surface disorders such as Stevens-Johnson syndrome, alkali burns, bullous or band keratopathy, ocular cicatricial pemphigoid, pterygium, and conjunctival tumors. ${ }^{36-39}$ In previously published reports, both fresh and preserved amniotic membrane has been shown to promote postoperative epithelization, attenuate the proinflammatory cascade, prevent neovascularization, and suppress recurrent subconjunctival fibrosis following symblepharon lysis. ${ }^{36-41}$

The amniotic membrane is known to differentiate into conjunctival epithelial cells, and amniotic membrane tissue provides a natural biological substrate for indigenous corneal stromal growth and epithelial cell differentiation with subsequent reduction in postoperative scar formation..$^{40,41,42} \mathrm{An}$ additional advantage of amniotic membrane transplantation is that it reduces postoperative pain because of the absence of any postoperative corneal epithelial defect. ${ }^{27}$ More significant corneal defects have also been filled and reconstructed using multilayered amniotic membrane tissue..$^{27,43}$ As an example, Handa et al examined the efficacy of amniotic membrane transplantation in the treatment of deep corneal and scleral ulcers. Of a total of 11 patients with deep corneal ulcers, $72.7 \%$ healed with epithelialization in $16.5 \pm 8.0$ days (range, 7 to 29 days), with five and three eyes showing corneal epithelialization and conjunctival epithelialization, respectively. The group concluded multilayered amniotic membrane transplantation may be effective for the treatment of deep ulceration of the cornea and sclera. ${ }^{34}$ The rationale for multilayered amniotic membrane transplantation is to augment complete volumetric filling of the defective area. Extensive corneal defects appear to show improved healing following multilayered amniotic membrane transplantation and augmentation. ${ }^{27,43}$

Recent advances in the use of fibrin glue in conjunction with amniotic membrane transplantation have significantly expanded the applicability of amniotic membrane transplantation in ocular surface reconstruction. ${ }^{44}$ Kim and Park in a retrospective case series of 10 patients with corneal perforations greater than $2 \mathrm{~mm}$ evaluated the efficacy of fibrin glue (FG)-assisted augmented amniotic membrane transplantation (AMT) in patients with large corneal perforations. They reported complete re-epithelization in $90 \%$ of patients without infection. They concluded FG-assisted augmented AMT was easily performed for repairing large corneal perforations. ${ }^{32}$ Tissue adhesives in amniotic membrane transplantation for pediatric corneal dermoid removal enable a sutureless surgical procedure and avoid

Table 2 Guarded recommendations for surgical removal of ocular dermoids

\begin{tabular}{ll}
\hline $\begin{array}{l}\text { Grade of pediatric limbal/corneal } \\
\text { dermoid }\end{array}$ & Recommended techniques \\
\hline $\begin{array}{l}\text { Grade I: }<50 \mu \mathrm{m} \text { thickness and } \\
<\mathrm{I} \mathrm{mm} \mathrm{diameter}\end{array}$ & Simple excision \\
Grade I: $<100 \mu \mathrm{m}$ thickness and & Keratectomy + AMT + ALSCA \\
$<\mathrm{I} \mathrm{mm} \mathrm{diameter}$ & \\
Grade II and deeper Grade I & Keratectomy + AMT + \\
& $\begin{array}{l}\text { LSCA + PPG versus anterior or } \\
\text { deep anterior lamellar } \\
\text { keratoplasty } \pm \text { AMT } \\
\text { Total anterior segment } \\
\text { reconstruction }\end{array}$ \\
\hline
\end{tabular}

Abbreviations: AMT, amniotic membrane transplantation (multilayered); ALSCA, autologous limbal stem cell allograft; PPG, pericardial patch graft. 
potential exposure of sutures, as well as reducing operating time. ${ }^{35}$ However, surgeons have to be mindful that if a child undergoing fibrin glue application has a tendency for eyerubbing (preoperatively or postoperatively), the multilayered amniotic membrane must be firmly secured with 10-0 running sutures at its borders using a double-pass technique to avoid early postoperative detachment and/or loss of the amniotic membrane. Clinical studies of this technique are ongoing. Panda also commented on advances and research on fresh versus preserved amniotic membrane transplantation in ophthalmology. ${ }^{33}$

For grade III limbal dermoids, complete anterior segment reconstruction must be anticipated. Anterior segment optical coherence tomography and high-resolution immersion B scan ultrasonography with or without orbital magnetic resonance imaging must be performed in anticipation of full penetrating keratoplasty with or without lensectomy, either staged or consecutively, with secondary intraocular lens implantation using intraoperative aberrometry to assess for feasibility of intraocular lens implantation and appropriate power. Enucleation or evisceration with subsequent orbital reconstruction has been proposed for grade III limbal dermoids where the globe is microphthalmic. ${ }^{2}$ Keratoprosthesis has been attempted in cases where dermoids accompany staphyloma, with mixed results.

Following a comprehensive review of the published literature, our recommendations as to which surgical procedure can be best used for each grade of pediatric limbal dermoid is summarized in Table 2.

\section{Future management of limbal dermoids}

Although indepth management of grade III limbal dermoids have been described in the literature, the surgical management of grade I and II limbal dermoids continues to evolve as a result of developing technology. Adjunctive therapeutic modalities with variously shaped femtosecond laser-assisted anterior lamellar keratoplasty versus Intralaseenhanced penetrating keratoplasty, deep anterior lamellar keratoplasty or topical application of a low-dose antimetabolite (ie, mitomycin C) after obtaining anterior segment optical coherence tomography with subsequent reconstruction are just some examples of where future clinical trials may take us in the near future in terms of the best surgical outcome following surgical excision of corneal or perilimbal dermoids. A combination of surgical approaches involving excision of the dermoid from the sclera and partial keratectomy followed by reconstructive steps using a pericardial patch graft on the sclera with overlying conjunctival autologous limbal stem cell transplantation and volumetric filling of the residual corneal defect with fresh multilayered amniotic membrane rather than lamellar keratoplasty (deep or superficial) may allow for the best functional, refractive, and cosmetic outcomes postoperatively.

\section{Disclosure}

The author reports no conflicts of interest in this work.

\section{References}

1. American Academy of Ophthalmology. Basic and Clinical Science Course. 2012. Series 6. Amercian Academy of Opthalmology.

2. Mansour AM, Barber JC, Reinecke RD, Wang FM. Ocular choristomas. Surv Ophthalmol. 1989;33:339-358.

3. Mohan M, Mukherjee G, Panda A. Clinical evaluation and surgical intervention of limbal dermoid. Indian J Ophthalmol. 1981;29: $69-73$.

4. Nevares RL, Mulliken JB, Robb RM. Ocular dermoids. Plast Reconstr Surg. 1988;82:959-964.

5. Burillon C, Duran L. Solid dermoids of the limbus and the cornea. Ophthalmologica. 1997;211:367-372.

6. Mann I. Developmental Abnormalities of the Eye. Cambridge, UK: Cambridge University Press; 1937.

7. Mann I. Developmental Abnormalities of the Eye. In: Mann I, 2nd ed. Philadelphia, PA: Lippincott; 1957.

8. Ash JE. Epibulbar tumors. Am J Ophthalmol. 1950;33:1203-1219.

9. Grossniklaus HE, Green WR, Lukenbach M, et al. Conjunctival lesions in adults: a clinical and histopathological review. Cornea. 1987;6: 78-116.

10. Mattos J, Contreras F, O’Donnell FE Jr. Ring dermoid syndrome. A new syndrome of autosomal dominantly inherited, bilateral, annual limbal dermoids with corneal and conjunctival extension. Arch Ophthalmol. 1980;98:1059-1061.

11. Malik SR, Gupta DK. Limbal dermoid with naevus flammeus and neurofibromatosis. Eye Ear Nose Throat Mon. 1967;46:612-614.

12. Garner A. The pathology of tumors at the limbus. Eye. 1989;3:210-217.

13. Robb RM. Astigmatic refractive errors associated with limbal dermoids. J Pediatr Ophthalmol Strabismus. 1996;33:241-243.

14. Bourne RA. Epibulbar dermoid tumours of the corneal limbus treated by lamellar keratoplasty. Trans Can Opthalmolog Soc. 1961;24: 153-158.

15. Zaidman GW, Johnson B, Brown SI. Corneal transplantation in an infant with corneal dermoid. Am J Ophthalmol. 1982;93:78-83.

16. Panton RW, Sugar J. Excision of limbal dermoids. Ophthalmic Surg. 1991;22:85-89.

17. Kaufman A, Medow N, Phillips R, Zaidman GJ. Treatment of epibulbar limbal dermoids. J Pediatr Ophthalmol Strabismus. 1999;36:136-140.

18. Lanzl IM, Augsburger JJ, Hertle RW, Rapauano C, Corea-Melling Z, Santa Cruz C. The role of ultrasound biomicroscopy in surgical planning for limbal dermoids. Cornea. 1998;17:604-606.

19. Hoops JP, Ludwig K, Boergen KP, Kampik A. Preoperative evaluation of limbal dermoids using high-resolution biomicroscopy. Graefes Arch Clin Exp Ophthalmol. 2001;239:459-461.

20. Grant CA, Azar D. Ultrasound biomicroscopy in the diagnosis and management of limbal dermoid. Am J Ophthalmol. 1999;128:365-367.

21. Scott JA, Tan DT. Therapeutic lamellar keratoplasty for limbal dermoids. Ophthalmology. 2001;108:1858-1867.

22. Shen YD, Chen WL, Wang IJ, Hou YC, Hu FR. Full-thickness central corneal grafts in lamellar keratoscleroplasty to treat limbal dermoids. Ophthalmology. 2005;112:1955. 
23. Watts P, Michaeli-Cohen A, Abdolell M, Rootman D. Outcome of lamellar keratoplasty for limbal dermoids in children. J AAPOS. 2002;6:209-215.

24. Panda A, Ghose S, Khokhar S, Das HJ. Surgical outcomes of epibulbar dermoids. J Pediatr Ophthalmol Strabismus. 2002;39:20-25.

25. Mader TH, Stulting D. Technique for the removal of limbal dermoids. Cornea. 1998;17:66-67.

26. Pirouzian A, Holz H, Merrill K, Sudesh R, Karlen K. Surgical management of pediatric limbal dermoids with sutureless amniotic membrane transplantation and augmentation. J Pediatr Ophthalmol Strabismus. 2012;49:114-119.

27. Pirouzian A, Ly H, Holz H, Sudesh RS, Chuck RS. Fibrin-glue assisted multilayered amniotic membrane transplantation in surgical management of pediatric corneal limbal dermoid: a novel approach. Graefes Arch Clin Exp Ophthalmol. 2011;249:261-265.

28. Hong S, Kim EJ, Seong GJ, Seo K. Limbal stem cell transplantation for limbal dermoid. Ophthalmic Surg Laser Imaging. 2010;9:1-2.

29. Tseng SC, Prabhasawat P, Barton K, Gray T, Meller D. Amniotic membrane transplantation with or without limbal allografts for corneal surface reconstruction in patients with limbal stem cell deficiency. Arch Ophthalmol. 1998;116:431-441.

30. Lazzaro DR, Coe R. Repair of limbal dermoid with excision and placement of circumlimbal pericardial graft. Eye Contact Lens. 2010;36: 228-229.

31. Koizumi N, Fullwood NJ, Bairaktaris G, Inatomi T, Kinoshita S, Quantock AJ. Cultivation of corneal epithelial cells on intact and denuded human amniotic membrane. Invest Ophthalmol Vis Sci. 2000;41:2506-2513.

32. Kim HK, Park HS. Fibrin glue-assisted augmented amniotic membrane transplantation for the treatment of large noninfectious corneal perforations. Cornea. 2009;28:170-176.
33. Panda A. Amniotic membrane transplantation in ophthalmology (fresh v preserved tissue). Br J Ophthalmol. 1999;83:1410-1411.

34. Hanada K, Shimazaki J, Shimmura S, Tsubota K. Multilayered amniotic membrane transplantation for severe ulceration of the cornea and sclera. Am J Ophthalmol. 2001;131:324-331.

35. Ozcan AA. Autologous human fibrin glue in multilayered amniotic membrane transplantation. Ann Ophthalmol. 2008;40:107-109.

36. Tseng SC, Espana EM, Kawakita T, et al. How does amniotic membrane work? Ocul Surf. 2004;2:177-187.

37. Fernandes M, Sridhar MS, Sangwan VS, Rao GN. Amniotic membrane transplantation for ocular surface reconstruction. Cornea. 2005;24: 643-653.

38. Gomes JA, Romano A, Santos MS, Dua HS. Amniotic membrane use in ophthalmology. Curr Opin Ophthalmol. 2005;16:233-240.

39. Yildiz EH, Nurozler AB, Ozkan Aksoy N, Altiparmak UE, Onat M, Karaguzel H. Amniotic membrane transplantation: indications and results. Eur J Ophthalmol. 2008;18:685-690.

40. Chen Z, Yan J, Yang H, et al. Amniotic membrane transplantation for conjunctival tumor. Yan Ke Xue Bao. 2003;19:165-167.

41. Meller D, Tseng SC. Conjunctival epithelial cell differentiation on amniotic membrane. Invest Ophthalmol Vis Sci. 1999;40:878-886.

42. Connon CJ, Nakamura T, Quantock AJ, Kinoshita S. The persistence of transplanted amniotic membrane in corneal stroma. Am J Ophthalmol. 2006;141:190-192.

43. Rodríguez-Ares MT, Touriño R, López-Valladares MJ, Gude F. Multilayer amniotic membrane transplantation in the treatment of corneal perforations. Cornea. 2004;23:577-583.

44. Chan SM, Boisjoly H. Advances in the use of adhesives in ophthalmology. Curr Opin Ophthalmol. 2004;15:305-310.
Clinical Ophthalmology

\section{Publish your work in this journal}

Clinical Ophthalmology is an international, peer-reviewed journal covering all subspecialties within ophthalmology. Key topics include: Optometry; Visual science; Pharmacology and drug therapy in eye diseases; Basic Sciences; Primary and Secondary eye care; Patient Safety and Quality of Care Improvements. This journal is indexed on Submit your manuscript here: http://www.dovepress.com/clinical-ophthalmology-journal

\section{Dovepress}

PubMed Central and CAS, and is the official journal of The Society of Clinical Ophthalmology (SCO). The manuscript management system is completely online and includes a very quick and fair peer-review system, which is all easy to use. Visit http://www.dovepress.com/ testimonials.php to read real quotes from published authors. 